\title{
Flowability, Rehydration Behaviour and bioactive Compounds of an Orange Powder Product as Affected by Particle Size
}

\author{
M. M. Camacho ${ }^{1} \cdot$ M. A. Silva-Espinoza ${ }^{1} \cdot$ N. Martínez-Navarrete ${ }^{1}$ (D)
}

Received: 5 November 2021 / Accepted: 24 January 2022 / Published online: 14 February 2022

(c) The Author(s) 2022

\begin{abstract}
By offering a powder that ensures the healthy value of the fruits, a proper flowability and adequate viscosity after rehydration, there could be an opportunity to promote fruit consumption. The particle size is of critical importance with regard to the properties of a powder. But the separation of a product by particle size is usually associated with compositional changes. In this study, an orange powder product with the same composition but different particle size was compared. The particle sizes considered $(269 \pm 4,189 \pm 4,118 \pm 3 \mu \mathrm{m})$ offer a product with the same bioactive compound content and guarantee a good powder flowability: angle of repose, compressibility, density, porosity and Hausner's and Carr's indexes. Nevertheless, grinding can be used as a simple green technology with which to adjust the particle size so as to obtain rehydrated products with differing viscosities and, therefore, powders with different applications: the smaller the particle size, the lower the viscosity.
\end{abstract}

Keywords Angle of repose $\cdot$ Bulk and tapped densities $\cdot$ Wettability $\cdot$ Viscosity $\cdot$ Vitamin C $\cdot$ Flavonoids

\section{Introduction}

We are all aware of the health benefits of eating fruit. However, there is a dearth of these foods in the human diet, which, at least in part, may be due to the fact that there are inconveniences involved in their consumption. The agri-food industry increasingly handles the production of food powders, and so, there is a need for information about their handling and processing characteristics (Ortega-Rivas, 2009). The availability of powdered fruit could help to encourage fruit eating by alleviating several of the disadvantages of fresh fruit consumption, such as difficulty of handling and short shelf-life stability. In fact, dried fruits and their application in powder form have been gaining more and more attention in the food industry (Karam et al., 2016).

Orange is an important food crop in many countries which enjoys wide acceptance around the world. There is a large amount of information regarding the human health benefits of eating oranges. These are not only the result of their composition in macronutrients, mainly fibre, but also

N. Martínez-Navarrete

nmartin@tal.upv.es

Food Technology Department, Food Investigation and Innovation Group, Universitat Politècnica de València, Camino de Vera s/n, 46022 Valencia, Spain because of their content in other bioactive compounds, such as vitamins and phytochemicals, which, although minor, seem to play an important role in the prevention of different diseases and various dysfunctions associated with ageing (Ma et al., 2020). Specifically, when we talk about oranges, we are talking about vitamin $\mathrm{C}$ and flavonoids, which seem to play an antioxidant role (Proteggente et al., 2002). Despite there being many references in the literature to the abovementioned characteristics, there is a lack of information as regards the physical, physicochemical, reconstitution and handling properties of an orange product in powder form, either offered as an ingredient for foods or consumed as a rehydrated formula.

As regards the powdered product, it is important to know some of the physical properties because it helps to understand its behaviour during storage, handling and processing (Ortega-Rivas, 2009). In this sense, different properties related to powder flowability are of interest so as to ensure the correct movement of bulk particles either relative to each other or along the container wall surface (Savlak \& Turker, 2020). This is the case of bulk and tapped densities, porosity, compressibility and angle of repose, among others. Nevertheless, as pointed out by Goh et al. (2018), powder flow remains as yet poorly understood. As suggested by Mitra et al. (2017), it is important to note that the flow characterisation techniques of many 
traditional powders result in poor repeatability and do not simulate dynamic processing conditions. In addition, water content can greatly affect these flow properties. On the other hand, for rehydration purposes, an adequate wettability, solubility and dispersibility of the powdered product must be ensured and once rehydrated, the viscosity must be considered.

It should be noted that powder particle size is of critical importance as regards the functional, reconstitution and handling properties (Savlak \& Turker, 2020). From this point of view, the degree of grinding may be employed as a suitable and user-friendly way to produce powders with outstanding properties, such as flowability and rehydration behaviour (Zhu et al., 2015). However, a distinction must be made between the powder obtained from the regular grinding of a product and the different granulometric classes that could be separated by sieving the ground product. The latter may lead to compositional variations between the different classes which may be responsible for differences in powder properties associated not only with the varying sizes but also with the different compositions (Alam et al., 2014; Jayadeep et al., 2009). Compositional changes, especially those related to the different fibre fractions, may also occur depending on the technology used to obtain the powder, as is the case with superfine grinding (Bender et al., 2020; Liu et al., 2016; Zhu et al., 2015).

Nevertheless, even when the grinding procedure is not expected to cause any compositional changes, it seems that the size does not always affect the behaviour of bulk powders in the same way. In this regard, despite the fact that larger and rounder particles are generally associated with better flow than small or irregular ones and a decrease in particle size may be associated with poorer flowability with an increased angle of repose (Goh et al., 2018; Horta de Oliveira et al., 2014; Lv et al., 2014), some other references justify the inverse relationship (Zhao et al., 2009; Zhong et al., 2016). As described by the authors referred to above, when varying the particle size one of two things may predominate, either the formation of aggregates or that of adhesive forces. This will depend on the product, its water content and the size range considered. Adjusting the particle size may also lead to modifications of the release of bioactive compounds, the behaviour of the powder against rehydration and the properties of the corresponding rehydrated formula ( $\mathrm{Lv}$ et al., 2014). Small particles usually display high surface areas, thus enhancing the release of phenolic compounds and promoting antioxidant capacity (Zhong et al., 2016; Zhu et al., 2015). In the case of powder products with the same composition, little information has been found that relates particle size to viscosity after rehydration. Lv et al. (2014) point to an increase in the viscosity of rehydrated mushroom as the powder particles become smaller, related to an increase in particle friction. Nevertheless,
Lundberg et al. (2014) related the increase in the viscosity of rehydrated citrus fibres to its larger fragments.

For all the above reasons, and from the point of view of handling a powder product, it is important to know the relationship between the particle size of each foodstuff, always within a specific size range, and its flowability and rehydration behaviour. The aim of this study was to analyse some quality attributes of an orange powder product as affected by the particle size. The orange product was obtained from the fruit puree with added gum Arabic and bamboo fibre as a means of preventing the development of stickiness and caking phenomena in the powder (Silva-Espinoza et al., 2020). The range of particle sizes corresponds to those obtained by a regular grinding process, so that no compositional changes were expected. As this powdered orange product could be used either as an ingredient in the formulation of other foods or for its further consumption as a beverage, both flowability and rehydration properties have been studied.

\section{Materials and Methods}

\section{Raw Materials}

Oranges (Citrus $\times$ sinensis cultivar Navel) were purchased in a local supermarket in the city of Valencia (Spain). The criteria of selection of the oranges were based on the homogeneity of size, colour, weight, and absence of physical external damage. Gum Arabic (GA, Scharlab, Sentmenat, Spain) and bamboo fibre (BF, VITACEL ${ }^{\circledR}$, Rosenberg, Germany) were used as drying agents to stabilise the orange powder, as suggested by Agudelo et al. (2017) and Silva-Espinoza et al. (2020).

\section{Obtaining Samples}

The oranges were washed and peeled, and the pulp was triturated $(40 \mathrm{~s}, 2000 \mathrm{rpm}$ and $40 \mathrm{~s}, 9200 \mathrm{rpm}$ (Thermomix TM21, Vorwerk, Barcelona, Spain) to obtain an orange puree. To prevent stickiness and caking of the powder that will finally be obtained, GA and BF were added in a ratio of 5 and $1 \mathrm{~g}$, respectively, per $100 \mathrm{~g}$ of orange puree (Silva-Espinoza et al., 2020). The mix was distributed in 3 aluminium plates, $25 \mathrm{~cm}$ in diameter and $1 \mathrm{~cm}$ thick (approximately $1000 \mathrm{~g}$ of sample per plate). The sample was frozen at $-45^{\circ} \mathrm{C}$ (freezer chest Liebherr Mediline LGT2325, Liebherr, Baden-Wurtemberg, Germany) for at least $24 \mathrm{~h}$, and freeze-dried at $5 \mathrm{~Pa},-45^{\circ} \mathrm{C}$ in a condenser and $50{ }^{\circ} \mathrm{C}$ as shelf temperature for $24 \mathrm{~h}$ (Telstar Lyo Quest-55 freeze dryer laboratory equipment, Telstar, Terrassa, Spain). Each of the three freeze-dried orange purees were ground to obtain an orange powder with differing average particle sizes, using sieves with meshes of 500, 300 and $200 \mu \mathrm{m}$. In the case of those powders sieved through the 500 or $300 \mu \mathrm{m}$ meshes, the freeze-dried cake was manually 
ground over each sieve, for the purposes of sieving as much sample through each as possible. In the case of the powder sieved through the $200 \mu \mathrm{m}$ mesh, the cake was ground (electric grinder Kenwood CH580, Barcelona, Spain). In all three cases, the small amount of sample that failed to pass through the respective sieves was incorporated into the powder set to ensure the same composition in each of the three powders.

\section{Analytical Determination}

\section{Water Content}

The water content (g water/100 g powder) of the powder sample was determined by using an automatic Karl Fisher titrator (Mettler Toledo, Compact Coulometric Titrator C10S, Worthington, OH, USA). Three replicates were taken per sample.

\section{Particle Size Distribution}

Three batches of approximately $40 \mathrm{~g}$ of each sample were passed through 12 sieves $(1600,1000,800,500,300,200$, $150,100,63,45,32$, and $25 \mu \mathrm{m}$ mesh, CISA 200/50, Barcelona, Spain), coupled with the cover and the bottom, using a sieving machine (RP 200 N CISA, Barcelona, Spain) to determine the particle size distribution. The powder retained in each sieve and in the bottom was weighed to determine both the relative frequency (\%) according to Eq. 1 and the mean particle size of each sample according to Eq. 2 .

Relative frequency $(\%)=\frac{w_{i}}{w} \times 100$

Average particle size $=\frac{\sum_{i}\left(A D_{i} \times w_{i}\right)}{w}$

$w_{i}$ being the weight of the powder retained in each sieve $(\mathrm{g}), w$ the sum of the weight of the powder retained in the different sieves and in the bottom (g), and $A D_{i}$ the average mesh diameter of the sieve in which the powder is retained and that of the previous one $(\mu \mathrm{m})$.

\section{Flowability}

Angle of Repose The angle of repose $\left(\mathrm{AoR},{ }^{\circ}\right)$ is the angle between the slope formed when the powder is poured into a funnel and the horizontal surface onto which the powder drops down. The angle was determined as described by SilvaEspinoza et al. (2021a, b). The AoR was calculated by measuring the diameter and height of the product cone formed (Eq. 3). Three replicates were carried out per sample.
$A o R=\arctan *\left(\frac{2 h}{d}\right)$

where $h=$ height from the top of the formed product cone to the horizontal surface $(\mathrm{cm}) ; d=$ maximum cone product diameter $(\mathrm{cm})$, taken as an average of at least 6 values.

Compressibility The compressibility of a product (b,/Pa) may be obtained from the variation of its apparent density when a mechanical compression test is carried out at low stress levels $\left(\sigma<90.807 \cdot 10^{4} \mathrm{~Pa}\right)$ (Eq. 4, Peleg, 1977). The variation of the apparent density was obtained using a texture analyser TA-XT (Stable Micro Systems, Surrey, UK) under the conditions described by Silva-Espinoza et al. $(2021 \mathrm{a}, \mathrm{b}))$

$\frac{\rho_{\sigma}-\rho_{0}}{\rho_{0}}=\frac{v_{0}-v_{\sigma}}{v_{\sigma}}=a+b \log \sigma$

where $\rho_{0}$ and $\mathrm{v}_{0}$ are the apparent density and the volume of the initial poured sample, $\rho_{\mathrm{s}}$ and $\mathrm{v}_{\mathrm{s}}$ are the apparent density and the volume of the sample under the normal stress applied at each moment ( $\sigma, \mathrm{Pa}$ ) and $a$ and $b$ are constants. Constant $b$ represents, specifically, the compressibility of a powder (/Pa).

Density, Porosity, Hausner and Carr Indexes The true, bulk and tapped densities were characterised. The calculation of the true density $\left(\rho, \mathrm{g} / \mathrm{cm}^{3}\right)$ was based on the sample composition (Eq. 5). The bulk density $\left(\rho_{\mathrm{B}}, \mathrm{g} / \mathrm{cm}^{3}\right)$ was evaluated as the ratio of the weight of the powder and the volume that it occupied. To obtain the tapped density $\left(\rho_{\mathrm{T}}, \mathrm{g} / \mathrm{cm}^{3}\right)$, the powder was poured into a graduated tube to a volume of $10 \mathrm{~mL}$ and submitted to a vibration process $(1200 \mathrm{rpm}$, $10 \mathrm{~s}$ ) in a vortex (Advanced Vortex Mixer, ZX3, VELP ${ }^{\circledR}$ SCIENTIFICA, Usmate (MB), Italy). The true and tapped density values were used to calculate the porosity $(\varepsilon, \%)$, and the Hausner and Carr indexes of each sample following Eqs. 6, 7 and 8, respectively. Four replicates were carried out for each of the three powders.

$\rho=\frac{1}{\frac{X_{w}}{\rho_{\mathrm{w}}}+\frac{X_{C H}}{\rho_{C H}}}$

where $\mathrm{x}_{\mathrm{w}}$ and $\mathrm{x}_{\mathrm{CH}}$ are the mass fractions of the two main components of each sample (water and carbohydrates, respectively; $\mathrm{x}_{\mathrm{w}}$ was determined by following the "Water Content" section and $\mathrm{x}_{\mathrm{CH}}$ by difference); $\rho_{\mathrm{w}}$ and $\rho_{\mathrm{CH}}$ are their densities ( $\rho_{\mathrm{CH}}=1,4246 \mathrm{~g} / \mathrm{cm}^{3}, \rho_{\mathrm{w}}=0,9976 \mathrm{~g} / \mathrm{cm}^{3}$, Okos, 1986).

$\varepsilon(\%)=100 \frac{\rho-\rho_{T}}{\rho}$

Hausner index $=\frac{\rho_{T}}{\rho_{B}}$ 
Carr index $=\frac{\rho_{T}-\rho_{B}}{\rho_{T}}$

\section{Bioactive Compounds}

Vitamin C Vitamin C (VC) was analysed considering its two active forms, ascorbic acid (AA) and its oxidized form, dehydroascorbic acid (DHAA). The sample AA was extracted with $0.1 \%$ oxalic acid (Scharlau, Spain). To know VC content DHAA was previously reduced to AA with dithiothreitol (DTT) (Sánchez-Mata et al., 2000; Sánchez-Moreno et al., 2003). DHAA was calculated by the difference between $\mathrm{VC}$ and AA content. The AA quantification was carried out according Xu et al. (2008) by using high-performance liquid chromatography (HPLC) (Jasco equipment, Italy), a KromaPhase $100-C 185 \mu \mathrm{m}$ column $(4.6 \times 250 \mathrm{~mm})$ (Scharlau, Spain) and the following chromatographic conditions: $10 \mu \mathrm{L}$ injection volume, $1 \mathrm{~mL} / \mathrm{min}$ flow rate and $0.1 \%$ oxalic acid as mobile phase. The identification was made at a wavelength of $243 \mathrm{~nm}$ (detector UV-visible MD-1510, Jasco equipment, Italy). Four replicates were carried out per sample.

Hesperidin and Narirutin Hesperidin (HES) and narirutin (NAT) was extracted from 0.075 of freeze-dried sample with $2 \mathrm{~mL}$ dimethylsulfoxide (DMSO) (Scharlau, Spain) grade HPLC and $1 \mathrm{~mL}$ double-distilled water (Gómez-Mejía et al., 2019; Manthey \& Grohmann, 1996). The quantification of HES and NAT was carried out by HPLC, at a wavelength of $284 \mathrm{~nm}$, using a gradient of water and methanol grade HPLC (VWR, Spain) for the mobile phase. A SpeedCore C18 $2.6 \mu \mathrm{m}$ column (Jasco, Italy) was used. The injection volume was $10 \mu \mathrm{L}$, and the flow rate was $1 \mathrm{~mL} / \mathrm{min}$. Four replicates were carried out per sample.

\section{Rehydration Properties}

Wettability The wettability refers to the wetting time taken by all the powder particles to sink completely. The wettability is inversely related to the wetting time. $10 \mathrm{~g}$ of powder was discharged over $250 \mathrm{~mL}$ of distilled water at $25^{\circ} \mathrm{C} \pm 1$ contained in a $500-\mathrm{mL}$ glass beaker with an internal diameter of $85 \mathrm{~mm}$. The time (s) taken by all the particles to sink completely and disappear from the surface was recorded (IDF, 2014). Three replicates were carried out for each sample.

Rehydration and Rheological Behaviour The powder was rehydrated to obtain the equivalent product before it was freeze-dried. The water loss in the mix during freeze-drying was considered to be added to the powder to obtain a rehydrated product with a water content of $82 \%$. Once each powder sample was rehydrated at $20{ }^{\circ} \mathrm{C}$, the flow behaviour was obtained at $8{ }^{\circ} \mathrm{C}$, simulating the usual consumption tempera- ture of a refrigerated orange juice, by means of a controlled shear stress rheometer (Kinexus DSR, Malvern Panalytical, Malvern, UK) with a coaxial cylinder sensor system (Z34 DIN), coupled to a thermostatic bath (Viscotherm VT 10, Physica). The shear rate $(\dot{\gamma})$ was increased from 0 to $120 / \mathrm{s}$ and the shear stress $(\sigma, \mathrm{Pa})$ was recorded. The results were fitted to the Ostwald de Waele model (Eq. 9) in order to obtain the flow behaviour index (n) and the consistency index $\left(\mathrm{K}, \mathrm{Pa} \cdot \mathrm{s}^{\mathrm{n}}\right)$. Instead of calculating the apparent viscosity at a specific shear rate as a means of comparing the viscosity of the rehydrated samples, in this study it was calculated by applying the mean value theorem (Eq. 10) so as to give a representative value over the entire range (Silva-Espinoza et al., 2021a, b).

$\sigma=\mathrm{K}(\dot{\gamma})^{\mathrm{n}}$

$\eta=\frac{K}{n} \dot{\gamma} \max ^{(n-1)}$

where $\sigma$ is the shear stress $(\mathrm{Pa}), \dot{\gamma}$ is the shear rate $(/ \mathrm{s}), n$ is the flow behaviour index, $K$ is the consistency index $\left(\mathrm{Pa} \cdot \mathrm{s}^{\mathrm{n}}\right)$, $\dot{\gamma}_{\text {max }}$ is the maximum rate $=120 / \mathrm{s}$ and $\eta$ is the apparent viscosity $(\mathrm{Pa} \cdot \mathrm{s})$.

\section{Results and Discussion}

\section{Particle Size Distribution and Water Content}

As a result of the grinding and sieving used in this study, three powders with different particle size distributions were obtained (Fig. 1), which is reflected in the different mode, median and mean sizes of each of them $(p<0.05)$. The mean particle sizes were $269 \pm 4,189 \pm 4$ and $118 \pm 3 \mu \mathrm{m}$ for the sample sieved through 500, 300 and $200 \mu \mathrm{m}$ meshes, respectively. As described by Day et al. (2010) and Moelants et al. (2014), each of this particulate plant material samples may contain either cell fragments, single cells or cell clusters. For the discussion of the results, these sizes have been classified as coarse, medium and fine. The fine sample was also the one with the widest particle size distribution, which may be related to the different grinding method used in this case. As regards the water content, the fine and medium samples had similar values $(p>0.05), 2.1$ and $2.05 \mathrm{~g}$ water/100 $\mathrm{g}$ sample, respectively, which were lower than the $2.5 \mathrm{~g}$ water $/ 100 \mathrm{~g}$ sample shown by the coarse powder $(p<0.05)$. A slight change in the environmental conditions in the laboratory during sample grinding and sieving could account for these differences. However, in all cases the water content was below the critical water content for the onset of the glass transition of this product, the value being $0.031 \mathrm{~g}$ water/g sample 


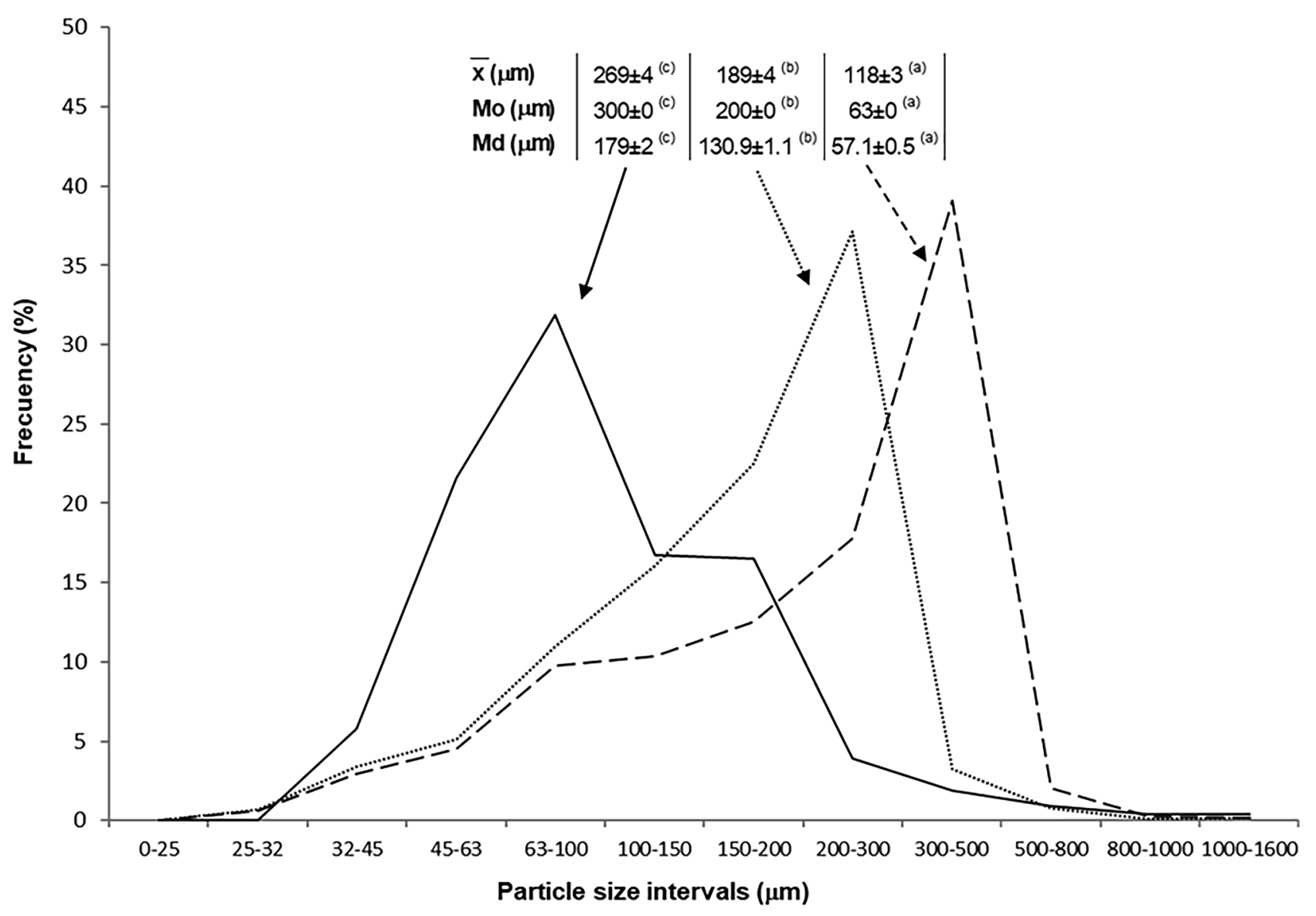

Fig. 1 Particle size distribution according to the ratio of weight of the retained sample in each sieve to total sample sieved (relative frequency, $\%$ ) for the samples with different mean particle size $(\bar{x}, \mu \mathrm{m})$,

(Silva-Espinoza et al., 2021a, b), so its effect on stickiness and powder agglomeration is not expected to be relevant. The calculated true density (Eq. 5) was not affected by the slight differences in the water content observed, this being $1.4112 \pm 0.0015 \mathrm{~g} / \mathrm{cm}^{3}$.

\section{Powder Flowability}

As regards the physical properties related to flowability measured in these samples (Table 1), the mean particle size was shown to be inversely related to both bulk density and tapped density, so that the smaller the size, the better the packing of the powder products and, therefore, the lower the interparticle porosity $(p<0.05$, Fig. 2$)$. A significant $(p=0.0002)$ positive Pearson correlation was observed between both properties $(r=0.933)$. Savlak and Turker (2020) also observed this trend when working with banana peel powder. Nevertheless, these authors described a sudden bulk density drop and porosity increase at sizes of under $74 \mu \mathrm{m}$, achieved by ultrafine grinding, which was attributed to the quick collapse shown by mode $(\mathrm{Mo}, \mu \mathrm{m})$ and median $(\mathrm{Md}, \mu \mathrm{m})$. The different lowercase letter within rows indicates different homogeneous groups established by the ANOVA $(p<0.05)$

these small cohesive particles. The fact that this change in tendency was not observed in the current study may indicate that the size range tested in this study does not lead to a significant development of stickiness and product agglomeration. In any case, the difference in porosity between the fine and medium samples was much greater than between the medium and coarse samples. The wider span of the particle size distribution of the fine sample probably contributes to its much lower porosity, as it is easier for the smaller particles to occupy the void spaces during compaction.

However, the angle of repose, compressibility, and the Hausner and Carr indexes did not show such a clear relationship with the mean particle size (Table 1). As regards AoR, values between 40.9 and $43.5^{\circ}$ are considered to be somewhat cohesive but with acceptable flowability (BarbosaCánovas et al., 2005), the medium-sized sample being the one that showed the lowest angle $(p<0.05)$. When the values of the Hausner and Carr indexes are taken into account, the medium sample would be a free-flowing powder (excellent flowability), the coarse would be in the easily fluidised group 
Table 1 Values

(mean \pm standard deviation) of the different properties related to the flowability of the fine $(118 \pm 3 \mu \mathrm{m})$, medium $(189 \pm 4 \mu \mathrm{m})$ and coarse $(269 \pm 4 \mu \mathrm{m})$ powders

\begin{tabular}{lccc}
\hline Property & \multicolumn{3}{l}{ Particle size } \\
\cline { 2 - 4 } & Fine & Medium & Coarse \\
\hline Bulk density $(\mathrm{g} / \mathrm{mL})$ & $0.467 \pm 0.012(\mathrm{c})$ & $0.344 \pm 0.008(\mathrm{~b})$ & $0.277 \pm 0.005(\mathrm{a})$ \\
Tapped density $(\mathrm{g} / \mathrm{mL})$ & $0.586 \pm 0.012(\mathrm{c})$ & $0.370 \pm 0.002(\mathrm{~b})$ & $0.311 \pm 0.002(\mathrm{a})$ \\
Angle of repose $\left(^{\circ}\right)$ & $42.9 \pm 0.9(\mathrm{~b})$ & $40.9 \pm 0.5(\mathrm{a})$ & $43.5 \pm 0.2(\mathrm{~b})$ \\
Compresibility $(\mathrm{N} / \mathrm{mm})$ & $0.122 \pm 0.019(\mathrm{ab})$ & $0.105 \pm 0.005(\mathrm{a})$ & $0.132 \pm 0.008(\mathrm{~b})$ \\
Hausner index & $1.255 \pm 0.009(\mathrm{c})$ & $1.07 \pm 0.02(\mathrm{a})$ & $1.12 \pm 0.02(\mathrm{~b})$ \\
Carr index & $0.203 \pm 0.006(\mathrm{c})$ & $0.068 \pm 0.016(\mathrm{a})$ & $0.108 \pm 0.014(\mathrm{~b})$ \\
\hline
\end{tabular}

The different lowercase letter within rows indicates different homogeneous groups established by the ANOVA $(p<0.05)$ (good flowability) and the fine would flow but with some difficulty (regular flow) (Barbosa-Cánovas et al., 2005; Royal Spanish Pharmacopoeia, 2015). In the case of the fine and medium samples, as the particle size increased, the value of all the properties shown in Table 1 decreased, which suggests a better flowability (Savlak \& Turker, 2020; Tay et al., 2016). This is the pattern to be expected when gravitational forces overcome attractive interparticle forces, such as Wan der Waals forces (Lv et al., 2014; Tay et al., 2016). Nevertheless, the highly cohesive nature of very fine powders has been observed to prevent the correct flow of the powder through the funnel when measuring AoR, so that the heaps created would not be stable and may collapse to produce much shallower cones (Tay et al., 2016).

From this point of view, the fact that the fine sample had a higher AoR than the medium in this study (Table $1, p<0.05$ ) again points to the fact that the smallest particle size does not lead to a powder that is too cohesive. The coarse sample had the same AoR as the fine $(p>0.05)$, which could be justified by the larger size of the fragments of the orange pulp's own fibre. Their cross-linking during powder handling could hinder the proper powder flowability, thus increasing the angle of repose as well as the compressibility and the Hausner and Carr indexes (Table 1, $p<0.05$ ).

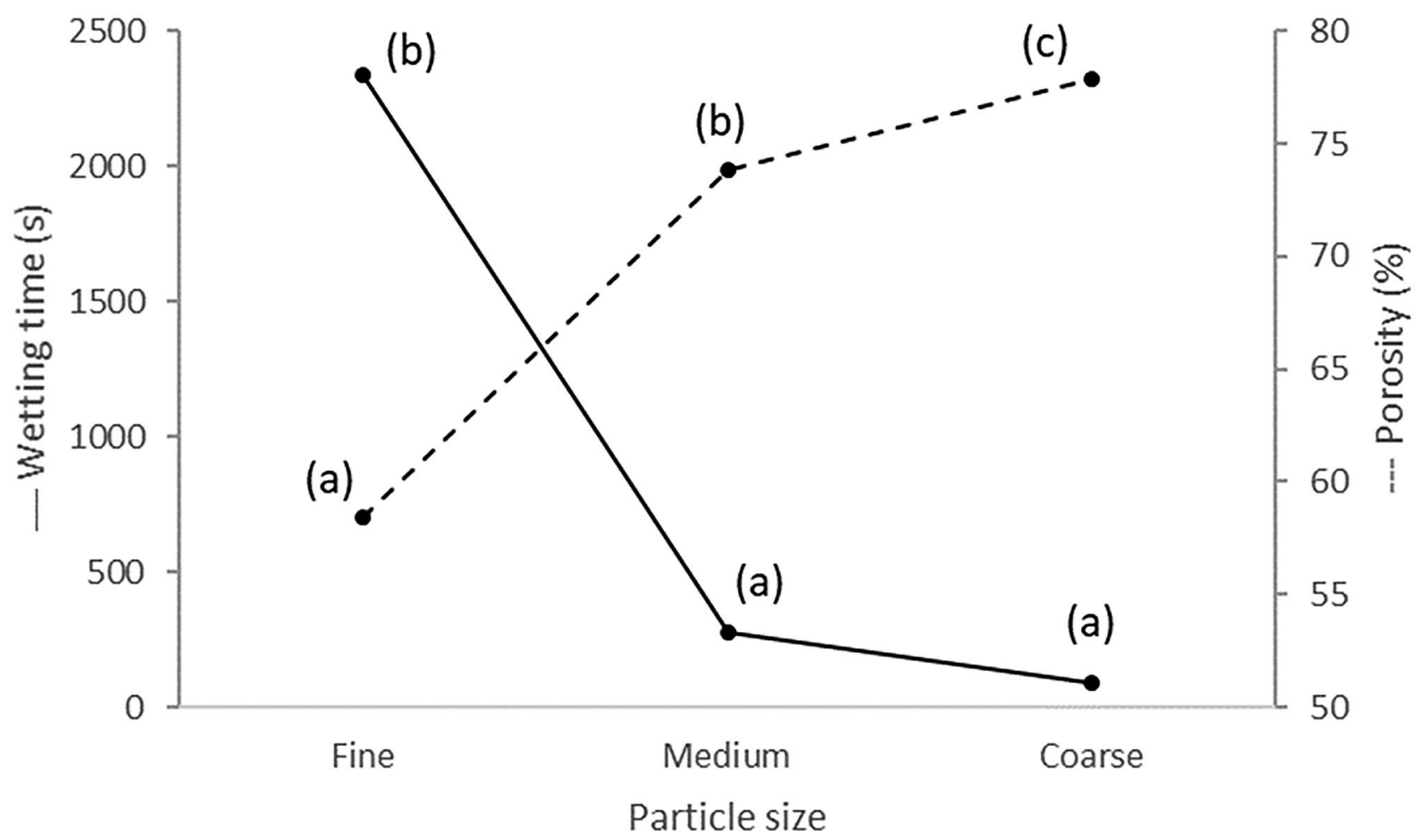

Fig. 2 Values (mean \pm standard deviation) of the wetting time and porosity for powder samples with different mean particle size: fine $(118 \pm 3 \mu \mathrm{m})$, medium $(189 \pm 4 \mu \mathrm{m})$ and coarse $(269 \pm 4 \mu \mathrm{m})$. Differ- ent letters indicate different homogeneous groups established by the ANOVA $(p<0.05)$ 
Table 2 Values (mean \pm standard deviation) of the different analysed bioactive compounds of the fine $(118 \pm 3 \mu \mathrm{m})$, medium $(189 \pm 4 \mu \mathrm{m})$ and coarse $(269 \pm 4 \mu \mathrm{m})$ powders

\begin{tabular}{llll}
\hline mg/100 g sample & \multicolumn{3}{l}{ Particle size } \\
\cline { 2 - 4 } & Fine & Medium & Coarse \\
\hline Vitamin C & $360 \pm 6(\mathrm{a})$ & $360 \pm 4(\mathrm{a})$ & $358 \pm 3(\mathrm{a})$ \\
Ascorbic acid & $273 \pm 15(\mathrm{a})$ & $275 \pm 4(\mathrm{a})$ & $269 \pm 7(\mathrm{a})$ \\
Dehydroascorbic acid & 87 & 85 & 89 \\
Hesperidin & $205 \pm 4(\mathrm{~b})$ & $193 \pm 3(\mathrm{a})$ & $193 \pm 3(\mathrm{a})$ \\
Narirutin & $127 \pm 2(\mathrm{~b})$ & $127.0 \pm 1.3(\mathrm{~b})$ & $123.8 \pm 1.8(\mathrm{a})$ \\
\hline
\end{tabular}

The different lowercase letter within rows indicates different homogeneous groups established by the ANOVA $(p<0.05)$

\section{Bioactive Compounds}

The bioactive compounds analysed in the powders with the three particle sizes are listed in Table 2. As can be observed, no differences were found either in the vitamin $\mathrm{C}$ content, or in that of AA or DHAA $(p>0.05)$. Nevertheless, greater quantities of the flavonoids hesperidin and narirutin were extracted in the smaller powders $(p<0.05)$. The same behaviour may even be observed when comparing the content of the different bioactive compounds on a dry basis. The ease with which the different compounds are extracted may justify the different behaviour. The greater solubility of VC would explain the absence of any significant differences among samples. In the case of the more insoluble hesperidin and narirutin, Zhong et al. (2016) also detected an improvement in flavonoid release as pomegranate peel powder particles became smaller, a phenomenon which could be attributed to the fact that the specific surface area increases as a result of the reduction in particle size. Nevertheless, these authors found that the total content of polyphenols and flavonoids in the samples with different particle sizes was nearly identical when the extraction time was extended. From this point of view, it does not appear that the particle sizes used in this study affect the chemical composition of this product.

\section{Rehydration Properties}

As regards the rehydration behaviour of the orange powders, the smaller the particle size, the worse the wettability (Fig. 2) and the lower the viscosity of the rehydrated product (Fig. 3). Several studies have reported that more intense grinding, leading to smaller particle sizes, may be related to a redistribution of the dietary fibre fractions in such a way that part of the insoluble

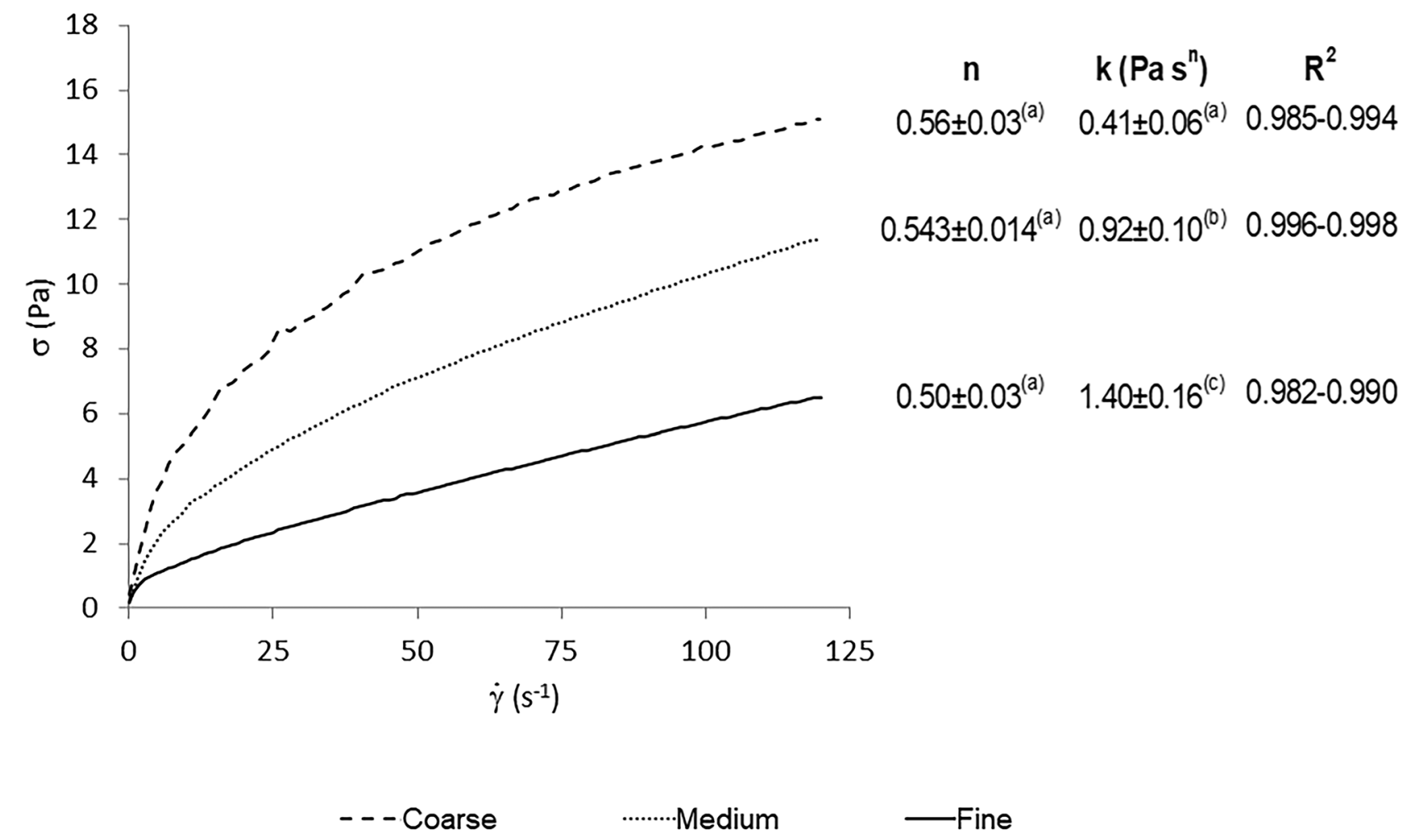

Fig. 3 Flow curves: shear stress $(\sigma)$ vs. shear rate $(\dot{\gamma})$ of one of the replicates of the rehydrated fine $(118 \pm 3 \mu \mathrm{m})$, medium $(189 \pm 4 \mu \mathrm{m})$ and coarse $(269 \pm 4 \mu \mathrm{m})$ powders. Mean values (and standard deviation) of flow behaviour index $(n)$, consistency index $\left(K, \mathrm{~Pa} \mathrm{~s}^{\mathrm{n}}\right)$ and apparent viscosity calculated through the mean value theorem $(\eta, \mathrm{Pa}$ $\mathrm{s})$. The different lowercase letter within columns indicates different homogeneous groups established by the ANOVA $(p<0.05)$ 
fraction degrades to soluble, which would improve its wettability (Lu et al., 2020; Speroni et al., 2020). However, in this case, all the samples showed $16.4^{\circ}$ Brix after rehydration, which seems to indicate that the grinding did not lead to a redistribution of fibre components into soluble and insoluble. A negative and significant $(p=0.0019)$ Pearson correlation was observed between mean particle size and wetting time $(r=-0.878)$. The long wetting time of the fine powder $(2340 \pm 216 \mathrm{~s})$ may be related to the increase in particle surface area, which promotes stronger adhesion forces of the finer particles leading to a tendency to agglomerate on the surface of the liquid (Schubert, 1987). In addition, the fact that the fine powder showed a much lower interparticle porosity makes it more difficult for water to penetrate by capillarity and come into contact with the entire surface of the particles (Fitzpatrick et al., 2016). In fact, a strong negative Pearson correlation ( $p=0.0000, r=-0.9850$ ) was also found between wetting time and porosity.

A significant $\eta$ increase in the rehydrated powder was observed as the particles became bigger $(p<0.05)$, the obtained values being $0.088 \pm 0.005,0.189 \pm 0.014$ and $0.253 \pm 0.007 \mathrm{~Pa}$ s for the fine, medium and coarse rehydrated samples, respectively. If the apparent viscosity of some commercial orange juices is taken as a reference, it varies between 0.0032 and 0.041 Pa s (Silva-Espinoza et al., 2021a, b), values close to the apparent viscosity of the fine rehydrated powder. Taking into account that the rehydrated products characterised in this study come from fruit puree, the greater presence of fibre than in a conventional juice is what increases its viscosity. However, with a smaller particle size, it is possible to obtain a product similar in viscosity to a commercial juice but with a higher nutritional and functional value due to its higher fibre content. In addition to temperature, the viscosity of a fluid is influenced by the quantity and type of soluble and insoluble solutes. Also, particle size and type appear to be key structural parameters controlling the rheology of plant-based food suspensions (Moelants et al., 2013). In this case, where the only change associated with more intense grinding appears to be the reduction in fibre length, with no change in its solubility, what is observed is that the smaller the fibre, the lower the viscosity of the rehydrated product. The same trend was found by Lundberg et al. (2014), who underline the significant impact of the physical size of citrus fibres on the apparent viscosity. The better reorientation of the smaller particles in the direction of the flow when imposing the shear movement would justify this behaviour.

\section{Conclusions}

The three particle sizes considered in this study do not change the chemical composition of the orange product and seem to be an adequate means of ensuring a good powder flowability; the one with a mean size of $189 \pm 4 \mu \mathrm{m}$ demonstrated the best properties in this respect. The larger fragment size of the orange pulp's own fibre when the particle size is increased, hinders the powder flow both in air and in water. The particle size can be used to adjust the viscosity of the rehydrated powder. With smaller particles, the viscosity decreases and, although the wetting time is extended in this case, it could be improved by proper agitation.

\section{Industrial Relevance}

Oranges are a very popular fruit both for fresh consumption and as jam or juice. However, the handling of fresh fruit has significant disadvantages for retailers as well as for consumers. In this sense, the supply of fruit powders can help to promote its consumption, currently at a low level, either as a food ingredient or after rehydration. The powder product must ensure the nutritional and functional quality of the fruits, as well as demonstrate good flowability and ensure an adequate viscosity after rehydration. The relevance of this study, from an industrial point of view, is that grinding can be used as a simple, green technology with which to maintain the composition of the orange powder, while varying its properties. The most interesting aspect of the findings is that by adjusting the particle size of the powder, it is possible to obtain rehydrated products of differing viscosities and, therefore, powders with different applications.

Funding Open Access funding provided thanks to the CRUE-CSIC agreement with Springer Nature. This study is financially supported by the Ministerio de Economía, Industria y Competitividad of Spain through the Project AGL 2017-89251-R (AEI/FEDER-UE).

Data Availability The data that support the findings of this study are available from the corresponding author upon reasonable request.

\section{Declarations}

Conflict of Interest The authors declare no competing interests.

Open Access This article is licensed under a Creative Commons Attribution 4.0 International License, which permits use, sharing, adaptation, distribution and reproduction in any medium or format, as long as you give appropriate credit to the original author(s) and the source, provide a link to the Creative Commons licence, and indicate if changes were made. The images or other third party material in this article are included in the article's Creative Commons licence, unless indicated otherwise in a credit line to the material. If material is not included in the article's Creative Commons licence and your intended use is not permitted by statutory regulation or exceeds the permitted use, you will need to obtain permission directly from the copyright holder. To view a copy of this licence, visit http://creativecommons.org/licenses/by/4.0/. 


\section{References}

Agudelo, C., Igual, M. M., Camacho, M. M., \& Martínez-Navarrete, N. (2017). Effect of process technology on the nutritional, functional, and physical quality of grapefruit powder. Food Science and Technology International, 23, 61-74. https://doi.org/10.1177/ 1082013216658368

Alam, S. A., Järvinen, J., Kirjoranta, S., Jouppila, K., Poutanen, K., \& Sozer, N. (2014). Influence of particle size reduction on structural and mechanical properties of extruded rye bran. Food and Bioprocess Technology, 7, 2121-2133. https://doi.org/10.1007/ s11947-013-1225-2

Barbosa-Cánovas, G. V., Ortega-Rivas, E., Juliano, P., \& Yan, H. S. (2005). Food powders: physical properties, processing, and functionality. Kluwer Academic/Plenum

Bender, A. B. B., Speroni, C. S., Moro, K. I. B., Morisso, F., dos Santos, D., da Silva, L. P., \& Penna, N. (2020). Effects of micronization on dietary fiber composition, physicochemical properties, phenolic compounds, and antioxidant capacity of grape pomace and its dietary fiber concentrate. LWT - Food Science and Technology, 117, 108652. https://doi.org/10.1016/j.lwt.2019.108652

Day, L., Xu, M., Oiseth, S. K., Hemar, Y., \& Lundin, L. (2010). Control of morphological and rheological properties of carrot cell wall particle dispersions through processing. Food and Bioprocess Technology, 3, 928-934. https://doi.org/10.1007/ s11947-010-0346-0

Fitzpatrick, J. J., van Lauwe, A., Coursol, M., O’Brien, A., Fitzpatrick, K. L., Ji, J., \& Miao, S. (2016). Investigation of the rehydration behaviour of food powders by comparing the behaviour of twelve powders with different properties. Powder Technology, 297, 340 348. https://doi.org/10.1016/j.powtec.2016.04.036

Goh, H. P., Heng, P. W. S., \& Liew, C. V. (2018). Comparative evaluation of powder flow parameters with reference to particle size and shape. International Journal of Pharmaceutics, 547, 133-141. https://doi.org/10.1016/j.ijpharm.2018.05.059

Gómez-Mejía, E., Rosales-Conrado, N., León-González, M. E., \& Madrid, Y. (2019). Citrus peels waste as a source of value-added compounds: Extraction and quantification of bioactive polyphenols. Food Chemistry, 295(289), 299. https://doi.org/10.1016/j. foodchem.2019.05.136

Horta de Oliveira, G. H., Corrêa, P. C., Santos, F. L., Vasconcelos, W. L., Calil-Júnior, C., Machado-Baptestini, F., \& Vargas-Elías, G. A. (2014). Physical characterization of coffee after roasting and grinding. Semina: Ciências Agrárias, 35, 1813-1828. https://doi. org/10.5433/1679-0359.2014v35n4p1813

IDF. (2014). Instant dried milk - Determination of the dispersibility and wettability. IDF 087. International Dairy Foundation.

Jayadeep, A., Singh, V., Sathyendra Rao, B. V., Srinivas, A., \& Ali, S. Z. (2009). Effect of physical processing of commercial de-oiled rice bran on particle size distribution, and content of chemical and bio-functional components. Food and Bioprocess Technology, 2, 57-67. https://doi.org/10.1007/s11947-008-0094-6

Karam, M. C., Petit, J., Zimmer, D., Baudelaire-Djantou, E., \& Scher, J. (2016). Effects of drying and grinding in production of fruit and vegetable powders: A review. Journal of Food Engineering, 188, 32-49. https://doi.org/10.1016/j.jfoodeng.2016.05.001

Liu, Y., Wang, L., Liu, F., \& Pan, S. (2016). Effect of grinding methods on structural, physicochemical, and functional properties of insoluble dietary fiber from orange peel. International Journal of Polymer Science, 2016, 6269302. https://doi.org/10.1155/2016/ 6269302

Lu, Z., Ye, F., Zhou, G., Gao, R., Qin, D., \& Zhao, G. (2020). Micronized apple pomace as a novel emulsifier for food o/w pickering emulsion. Food Chemistry, 330, 127325. https://doi.org/10.1016/j. foodchem.2020.127325
Lundberg, B., Pan, X., White, A., Chau, H., \& Hotchkiss, A. (2014). Rheology and composition of citrus fiber. Journal of Food Engineering, 125, 97-104. https://doi.org/10.1016/j.jfoodeng.2013. 10.021

Lv, G., Zhang, Z., Pan, H., \& Fan, L. (2014). Effect of physical modification of mushroom (A. chaxingu) powders on their physical and chemical properties. Food Science and Technology Research, 20, 731-738. https://doi.org/10.3136/fstr.20.731

Ma, G., Zhang, L., Sugiura, M., \& Kato, M. (2020). Chapter 24 - Citrus and health. Woodhead Publishing. https://doi.org/10. 1016/B978-0-12-812163-4.00024-3

Manthey, J. A., \& Grohmann, K. (1996). Concentrations of hesperidin and other orange peel flavonoids in citrus processing byproducts. Journal of Agricultural and Food Chemistry, 44(3), 811-814. https://doi.org/10.1021/jf950572g

Mitra, H., Pushpadass, H. A., Franklin, M. E. E., Ambrose, R. P. K., Ghoroi, C., \& Battul, S. N. (2017). Influence of moisture content on the flow properties of basundi mix. Powder Technology, 312, 133-143. https://doi.org/10.1016/j.powtec.2017.02.039

Moelants, K. R. N., Cardinaels, R., Jolie, R. P., Verrijssen, T. A. J., Van Buggenhout, S., Zumalacarregui, L. M., et al. (2013). Relation between particle properties and rheological characteristics of carrot-derived suspensions. Food and Bioprocess Technology, 6, 1127-1143. https://doi.org/10.1007/s11947-011-0718-0

Moelants, K. N., Cardinaels, R., Jolie, R., Verrijssen, T. J., Buggenhout, S., Loey, A., Moldenaers, P., \& Hendrickx, M. (2014). Rheology of concentrated tomato-derived suspensions: Effects of particle characteristics. Food and Bioprocess Technology, 7, 248-264. https://doi.org/10.1007/s11947-013-1070-3

Okos, M. R. (1986). Physical and chemical properties of food. American Society of Agricultural Engineers.

Ortega-Rivas, E. (2009). Bulk properties of food particulate materials: an appraisal of their characterisation and relevance in processing. Food and Bioprocess Technology, 2, 28-44. https://doi. org/10.1007/s11947-008-0107-5

Peleg, M. (1977). Flowability of food powders and methods for its evaluation. Journal of Food Process Engineering, 1, 303-328. https://doi.org/10.1111/j.1745-4530.1977.tb00188.x

Proteggente, A. R., Sekher-Pannala, A., Paganga, G., van Buren, L., Wagner, E., Wiseman, S., van de Put, F., Dacombe, C., \& RiceEvans, C. A. (2002). The antioxidant activity of regularly consumed fruit and vegetables reflects their phenolic and vitamin C composition. Free Radical Research, 36(2), 217-233. https:// doi.org/10.1080/10715760290006484

Royal Spanish Pharmacopoeia. (2015). Ministerio de Sanidad, Servicios. Sociales e Igualdad. Retrieved Accessed July 6, 2021, from http:// tienda.boe.es/Farmacopea_index.html

Sánchez-Mata, M. C., Cámara-Hurtado, M., Díez-Marqués, C., \& Torija-Isasa, M. E. (2000). Comparison of high-performance liquid chromatography and spectrofluorimetry for vitamin $\mathrm{C}$ analysis of green beans (Phaseolus vulgaris L.). European Food Research and Technology, 210(3), 220-225. https://doi.org/10. 1007/PL00005516

Sánchez-Moreno, C., Plaza, L., de Ancos, B., \& Cano, M. P. (2003). Quantitative bioactive compounds assessment and their relative contribution to the antioxidant capacity of commercial orange juices. Journal of the Science of Food and Agriculture, 83(5), 430-439. https://doi.org/10.1002/jsfa.1392

Savlak, N., \& Turker, B. (2020). Particle size affects physical properties and antioxidant activity of unripe banana peel. Fresenius Environmental Bulletin, 29(3), 1677-1685. https://doi.org/10. 1016/j.foodchem.2016.06.064

Schubert, H. (1987). Food particle technology. Part 1: Properties of particles and particulate food systems. Journal of Food 
Engineering, 6, 1-32. https://doi.org/10.1016/0260-8774(87) 90019-7

Silva-Espinoza, M. A., Ayed, C., Camacho, M. M., Foster, T., \& MartínezNavarrete, N. (2021a). Impact of maltodextrin, gum Arabic, different fibres and starches on the properties of freeze-dried orange puree powder. Food Biophysics, 16, 270-279. https://doi.org/10.1007/ s11483-021-09667-x

Silva-Espinoza, M. A., Camacho, M. M., \& Martínez-Navarrete, N. (2020). Use of different biopolymers as carriers for purposes of obtaining a freeze-dried orange snack. LWT-Food Science and Technology, 127, 109415. https://doi.org/10.1016/j.1wt.2020.109415

Silva-Espinoza, M. A., Salvador, A., Camacho, M. M., \& MartínezNavarrete, N. (2021b). Impact of freeze-drying conditions on the sensory perception of a freeze-dried orange snack. Journal of Science and Food Agriculture, 101, 4585-4590. https://doi.org/10. 1002/jsfa.11101

Speroni, C. S., Bender, A. B. B., Stiebe, J., Ballus, C. A., Felix-Ávila, P., Goldbeck, R., Morisso, F., da Silva, L., \& Emanuelli, T. (2020). Granulometric fractionation and micronization: A process for increasing soluble dietary fiber content and improving technological and functional properties of olive pomace. LWT-Food Science and Technology, 130, 109526. https://doi.org/10.1016/j.lwt.2020. 109526

Tay, J. Y. S., Liew, C. V., \& Heng, P. W. S. (2016). Powder flow testing: Judicious choice of test methods. An Official Journal of the American Association of Pharmaceutical Scientists, 18, 1843-1854. https://doi.org/10.1208/s12249-016-0655-3
Xu, G., Liu, D., Chen, J., Ye, X., Ma, Y., \& Shi, J. (2008). Juice components and antioxidant capacity of citrus varieties cultivated in China. Food Chemistry, 106(2), 545-551. https://doi.org/10. 1016/j.foodchem.2007.06.046

Zhao, X., Yang, Z., Gai, G., \& Yang, Y. (2009). Effect of superfine grinding on properties of ginger powder. Journal of Food Engineering, 91(2), 217-222. https://doi.org/10.1016/j.jfoodeng.2008. 08.024

Zhong, C., Zu, Y., Zhao, X., Li, Y., Ge, Y., Wu, W., Zhang, Y., Li, Y., \& Guo, D. (2016). Effect of superfine grinding on physicochemical and antioxidant properties of pomegranate peel. International Journal of Food Science and Technology, 51, 212-221. https://doi. org/10.1111/ijfs. 12982

Zhu, F., Du, B., \& Xu, B. (2015). Superfine grinding improves functional properties and antioxidant capacities of bran dietary fibre from Qingke (hull-less barley) grown in Qinghai-Tibet Plateau, China. Journal of Cereal Science, 65, 43-47. https://doi.org/10. 1016/j.jcs.2015.06.006

Publisher's Note Springer Nature remains neutral with regard to jurisdictional claims in published maps and institutional affiliations. 